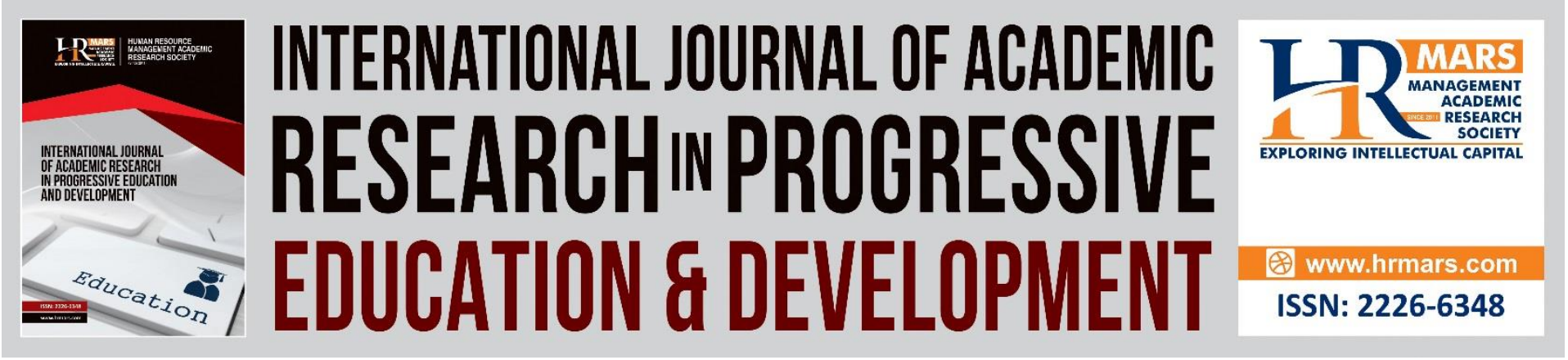

\title{
Enriching Student Learning Through Video-annotated Peer Feedback Activity: A Guide
}

Catherine Nguoi Chui Lam \& Hadina Habil

To Link this Article: http://dx.doi.org/10.6007/IJARPED/v10-i3/10712

DOI:10.6007/IJARPED/v10-i3/10712

Received: 09 June 2021, Revised: 13 July 2021, Accepted: 22 July 2021

Published Online: 09 August 2021

In-Text Citation: (Lam \& Habil, 2021)

To Cite this Article: Lam, C. N. C., \& Habil, H. (2021). Enriching Student Learning Through Video-annotated Peer Feedback Activity: A Guide. International Journal of Academic Research in Progressive Education and Development, 10(3), 46-60.

Copyright: (C) 2021 The Author(s)

Published by Human Resource Management Academic Research Society (www.hrmars.com)

This article is published under the Creative Commons Attribution (CC BY 4.0) license. Anyone may reproduce, distribute, translate and create derivative works of this article (for both commercial and non-commercial purposes), subject to full attribution to the original publication and authors. The full terms of this license may be seen

at: http://creativecommons.org/licences/by/4.0/legalcode

\section{Vol. 10(3) 2021, Pg. 46 - 60}

Full Terms \& Conditions of access and use can be found at http://hrmars.com/index.php/pages/detail/publication-ethics 


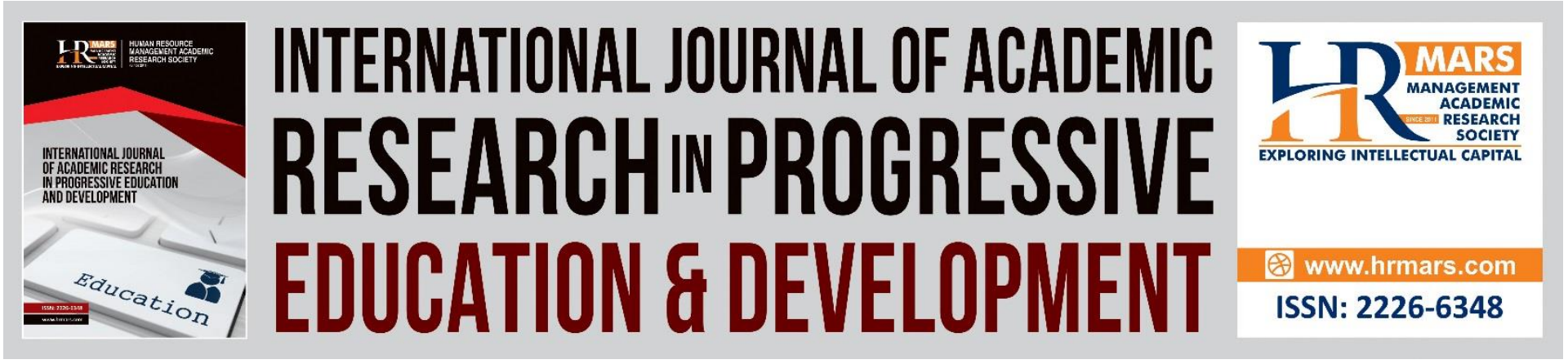

\title{
Enriching Student Learning Through Video- annotated Peer Feedback Activity: A Guide
}

\author{
Catherine Nguoi Chui Lam ${ }^{1} \&$ Hadina Habil ${ }^{2}$ \\ ${ }^{1}$ School of Education, Universiti Teknologi Malaysia, 81310 Skudai, Johor, Malaysia, \\ ${ }^{2}$ Language Academy, Universiti Teknologi Malaysia, 81310 Skudai, Johor, Malaysia.
}

\begin{abstract}
Despite the growing research base on the use of video annotation in education, little is known on how to coherently structure a video-annotated peer feedback activity to engage students. Eventhough some studies have outlined the guidelines for conducting video-based annotation practice, little has been published with the focus on video-annotated peer feedback. To explore this under-investigated realm, the current review was conducted. In order to identify studies to be included in this review, a strategy for literature search was initially developed. This was followed by the selection and categorization of relevant studies. This paper thus provides a succinct overview of the essential steps involved in conducting a video-annotated peer feedback learning activity. Most importantly, it has resulted in a guide that outlines those essential stages and steps, thus providing insights into adaptation for use in education.
\end{abstract}

Keywords: Peer Feedback, Video Annotation, Video Annotated Peer Feedback, Student Learning, Innovative Teaching.

\section{Introduction}

A video annotation (VA) tool is best recognized with its ability to match the textual messages to moments in a video (Howard, 2012). In other words, comments provided in a VA platform can be synced to the particular segments of a video. A more comprehensive definition of video annotation was provided by Evi-Colombo et al (2020) in their review paper. VA refers to "a web-based or standalone system that integrates commenting, video playback, and timebased textual or iconic annotation" (p.217). It can thus be used effectively to promote student learning as far as the use of video-based learning materials is concerned.

Though rigorous recent research activities were found to integrate the use of VA, particularly at tertiary level of education, the investigation into the process of videoannotated peer feedback activity is sparse. Moreover, though there were few attempts that illustrate the guidelines for conducting video-annotated practices (eg. Colasante \& Douglas, 2016), they do not focus on peer review and thus it is not easy to parse out what is specifically required from the learners when participating in a video-annotated peer feedback activity. Providing students with a clear set of guidelines can give them an overview of the whole process and enable them to anticipate the upcoming learning tasks so as to better prepare 
themselves. By analyzing the design of these related studies and their approaches to carry out the video-annotated peer feedback learning activities, the key phases and main steps can be identified and summarized for the development of a guide so as to provide a practice-based tool that can help practitioners to use as well as to enable other researchers to test and develop the guide further. Hence, the development of a video-annotated peer feedback activity guide is adamant. This review was thus conducted with the purpose to capture and describe the important stages and steps involved in conducting a video-annotated peer feedback activity. It thus seeks to answer the following research question: What were the essential steps involved in the video-annotated peer feedback activities in selected studies?

\section{Literature Review}

This section presents the literature on video annotation tools, framework for teaching with video annotation and a discussion on how video-annotated activities can be used to facilitate feedback process.

\section{Video Annotation as a Teaching and Learning Tool}

Literature reveals that a variety of VA tools and platforms have been developed, used or explored for educational purposes. As shown in Table 1, it is obvious that the three most commonly used VA tools were VideoANT, Media Annotation Tool (MAT) and Collaborative Lecture Annotation System (CLAS). Other platforms are Video-Annotated Listening Review Mechanism (VALRM), video-annotated learning and reviewing system with vocabulary learning mechanism (VALRS-VLM), video annotation learning system (VALS), collaborative educational video annotation, Annomation, VideoFragmentRating (VFR) system, Nursing Communication Peer Assessment (NCPA), Clipper, Collaborative Annotation Tool (CaTool) \& Open Video Annotation (OVA), the HyperVideo, Viddler, Celluloid, YouTube annotation tool, Go-React, educational video annotations/ Educational Video with collaborative Annotation (EVA) and video annotation learning platform (VALP). 
Table 1. Video annotation tools in previous studies

\begin{tabular}{|c|c|}
\hline Video Annotation (VA) Tool & Studies \\
\hline VideoANT & $\begin{array}{l}\text { Aguillon \& Monterola, 2020; Baepler \& Reynolds, 2014; Lee } \\
\text { \& List, 2019; Mcfadden et al., 2014; Van der Westhuizen \& } \\
\text { Golightly, } 2015\end{array}$ \\
\hline Media Annotation Tool (MAT) & $\begin{array}{l}\text { Colasante, 2011; Colasante \& Douglas, 2016; Douglas et al., } \\
\text { 2015; Colasante \& Leedham, 2013; Lemon et al., } 2013\end{array}$ \\
\hline Collaborative Lecture & Dawson et al., 2016; Joksimovic et al., 2019; Mirriahi et al., \\
\hline Annotation System (CLAS) & 2018 \\
\hline Video-Annotated Listening & Chen \& Chen, 2018 \\
\hline $\begin{array}{l}\text { Review Mechanism (VALRM) } \\
\text { video-annotated learning and } \\
\text { reviewing system with } \\
\text { vocabulary learning mechanism } \\
\text { (VALRS-VLM) }\end{array}$ & Chen, Li \& Lin, 2020 \\
\hline $\begin{array}{l}\text { video annotation learning } \\
\text { system (VALS) }\end{array}$ & Chiu et al., 2016 \\
\hline $\begin{array}{l}\text { collaborative educational video } \\
\text { annotation }\end{array}$ & Grunewald \& Meinel, 2015 \\
\hline Annomation (semantic) & Yu et al, 2012 \\
\hline $\begin{array}{l}\text { VideoFragmentRating (VFR) } \\
\text { system }\end{array}$ & Hulsman \& Van der Vloodt, 2015 \\
\hline $\begin{array}{l}\text { Nursing Communication Peer } \\
\text { Assessment (NCPA) }\end{array}$ & Lai et al., 2020 \\
\hline Clipper & Marcal et al., 2020 \\
\hline $\begin{array}{l}\text { Collaborative Annotation Tool } \\
\text { (CaTool) \& Open Video } \\
\text { Annotation (OVA) }\end{array}$ & Moya et al., 2015 \\
\hline iVideo (HyperVideo) & Perini et al., 2019 \\
\hline Viddler & Sherry et al., 2018 \\
\hline Celluloid & Tessier \& Tremion, 2020 \\
\hline YouTube annotation tool & Nilsson \& Karlsson, 2019 \\
\hline Go-React & Ardley \& Hallare, 2020; Ardley \& Johnson, 2018 \\
\hline Educational Video Annotations & Anderson et al., 2012 \\
\hline $\begin{array}{l}\text { (EVA) } \\
\text { Educational Video with } \\
\text { collaborative Annotation (EVA) }\end{array}$ & Wong \& Reimann, 2009 \\
\hline $\begin{array}{l}\text { video annotation learning } \\
\text { platform (VALP) }\end{array}$ & Zhang \& Wu, 2015 \\
\hline
\end{tabular}

The basic feature of VA tool is the time-marked text annotation and most of the VA tools also support tagging/labelling of users' comments. Some platforms allow creation of a catalogue of video annotations and sharing of the annotated clips (see Marcal et al., 2020). While MAT offers 'coloured markers' to categorise content (see Colasante \& Douglas, 2016; Douglas et al., 2015), collaborative educational video annotation also allows users to predefine default captions when implementing markers (see Grunewald \& Meinel, 2015). As 
for VALP, users can work on "embedded exercises," add "notes," and ask "questions" to the teacher via the platform (see Zhang \& Wu, 2016). NCPA, which was designed for assessing nursing communication also has 'mark buttons' for specifying the type of comment (see Lai et al., 2020). In VALS, users can work on annotations with pencil, line, arrow tool, rectangle, circle, textual and eraser tool. A variety of colours can also be used for each tool, making clearer annotations in video display area (see Chiu et al., 2016). Similarly, OVA has a lot of advanced features, such as multimedia annotations, sharing of annotations on social networks, tagging with geolocating feature and eRubrics (see Moya et al., 2015). EVA is another platform that offers a lot of friendly navigation and viewing features such as cuesegments which can display segments of video temporal bookmarks and an associated list of users' annotations (see Anderson et al., 2012; Wong \& Reimann, 2009). Apart from features such as visualisation of areas of student convergence and divergence and the inclusion of video-to-video annotations, CLAS allows users to annotate (point-based and text) a variety of multimedia content, such as podcasts, lecture capture and PowerPoint (see Dawson et al., 2016). Annomation, a semantic VA tool allows users to add linked data annotations so that the videos can be linked to other web resources (see Yu et al., 2012). Go-React is a for-pay cloud-based tool, with preset colored tabs and advanced features for rubric to be embedded for grading (see Ardley \& Johnson, 2018). Besides, attachments can also be uploaded to support the video (see Ardley \& Hallare, 2020). Apart from insertion of individual or collaborative video annotations, HyperVideo also supports linking of additional materials, such as documents, other videos or descriptions (see Perini et al., 2019). With VALRM, users can review marked sections with bilingual captions immediately or at a later stage to aid them in listening comprehension (see Chen \& Chen, 2018). Meanwhile, VALRS-VLM allows users to highlight unfamiliar words in subtitles and learn these words with a built-in online dictionary (see Chen et al., 2020). With password-protected video server, only the video owners and invited individuals can get access to the videos in VFR (see Hulsman \& Vloodt, 2015). Viddler, as highlighted in Sherry et al.,'s (2018) study also involves a secure online network, which comes with features, such as customizable viewer access, customizable content access and reports and alerts. In Celluloid, a code can be generated by the trainer and transmitted to the target group to work in a closed-space virtual classroom (see Tessier \& Tremion, 2020).

\section{Framework for Teaching with Video Annotation}

Colasante and Douglas (2016) proposed a framework for teaching with video annotation in tertiary education. The first step-preparation is concerned with designing and planning of the lesson, in which activities such as identifying the intended learning outcomes, determining appropriate videos, designing learning activities, preparing associated equipment and providing technological support were included. The second step - participation is related to the stage of implementing video-annotated practice in which activities such as students' meaningful exploration with the video interactive affordances, collaborative student work and teacher monitoring were outlined. As for the third step - connection, activities can be designed as such to establish connections of student learning to other topics, activities, and/or professional relevance or link-forward to other learning and vocational/ professional experiences. Drawing upon this framework, this review analyzed the essential steps involved when students are engaged in video-annotated peer feedback activities. 
DEVELOPMENT

Vol. 10, No. 3, 2021, E-ISSN: 2226-6348 @ 2021 HRMARS

\section{Video Annotation and Feedback Process}

The essential role played by VA tool in supporting evidenced-based discussions among the users has made it an effective tool to facilitate feedback process. As highlighted, the need to constantly watch the videos so as to associate comments with the video content will somehow help students in giving suggestive feedback like the experts (Lai et al., 2020). Besides, previous studies have evidenced 'better and more meaningful comments' (Baepler \& Reynolds, 2014), 'suggestive and beneficial feedback' consisting of 'suggestion' and 'goal' categories of comments (Lai et al., 2020) and 'more concrete and contextualized feedback' (Tülüce, 2018) with the use of video annotation. Furthermore, an enhanced validity of peer scores and student performances was also noted with the use of VA tool (Lai et al., 2020). These studies have thus suggested that video annotation can be used effectively to facilitate the feedback process. The development of a guide which maps out the essential steps involved in a video-annotated peer feedback activity will thus offer insights for future research and could benefit practitioners who are interested in using video annotation to facilitate students in the peer feedback activity.

\section{Method}

Following Pérez-Torregrosa et al (2017), a three-phase process which involves developing a strategy for literature search, selecting studies and categorization was performed. Searches were conducted in November 2020 using Scopus with two sets of key terms: (("video annotate*") AND (educat* OR teach* OR learn* OR student*)) which were chosen based on preliminary searches on the related literature. Google Scholar was used as the secondary database. In the first screening stage, video annotation studies which were conducted in education context, published between 2011 and 2020 and those with empirical data were selected.

Next, the selected articles were later classified into five (5) different categories, focusing on the nature and purpose of the video-annotated projects involving self-reflection purposes, collaborative classroom work, peer review, individual exploration of video content or integration of tutor /teacher/ expert feedback which were defined from the analysis. As a result, nine (9) of the studies, as listed in Table 2 were finally retained for coding and data extraction as they explicitly described the steps on how video-annotated peer feedback activities were conducted. 
Table 2. Selected studies in this review

\begin{tabular}{|c|c|c|c|}
\hline Study focus & Sample & Context & Studies \\
\hline $\begin{array}{l}\text { Transmedia navigation in } \\
\text { digital video assignment }\end{array}$ & $\begin{array}{l}\text { students from } 2 \\
\text { intermediate writing } \\
\text { courses at an R1 } \\
\text { institution }\end{array}$ & $\begin{array}{l}\text { Manifesto videos and } \\
\text { nature project videos } \\
\text { ( } 2 \text { portfolio projects) }\end{array}$ & $\begin{array}{l}\text { Baepler \& } \\
\text { Reynolds, } \\
2014\end{array}$ \\
\hline \multirow[t]{2}{*}{$\begin{array}{l}\text { Workplace/employment } \\
\text { skills development }\end{array}$} & $\begin{array}{l}\left({ }^{*}\right) \text { Property Service } \\
\text { (PO) vocational } \\
\text { students at RMIT } \\
\text { university }\end{array}$ & $\begin{array}{l}\text { Students' role-play } \\
\text { videos (owners } \\
\text { corporation meetings) }\end{array}$ & $\begin{array}{l}\text { Colasante \& } \\
\text { Douglas, } \\
2016\end{array}$ \\
\hline & $\begin{array}{l}(*) \text {-Education } \\
\text { (literacy) } \\
\text { undergraduates }\end{array}$ & $\begin{array}{l}\text { Videos on students' } \\
\text { draft book }\end{array}$ & $\begin{array}{l}\text { Lemon et al., } \\
2013\end{array}$ \\
\hline \multirow[t]{2}{*}{ Clinical practices } & $\begin{array}{l}25 \text { year- } 4 \text { medical } \\
\text { students }\end{array}$ & $\begin{array}{l}\text { Video-recorded } \\
\text { students' consultations } \\
\text { with a simulated } \\
\text { patient }\end{array}$ & $\begin{array}{l}\text { Hulsman \& } \\
\text { van der } \\
\text { Vloodt, } 2015\end{array}$ \\
\hline & $\begin{array}{l}50 \text { undergraduates } \\
\text { from a junior } \\
\text { nursing college } \\
\text { (experimental } \\
\text { group) }\end{array}$ & $\begin{array}{l}\text { Video-recorded } \\
\text { students' interviews } \\
\text { with simulated } \\
\text { patients }\end{array}$ & $\begin{array}{l}\text { Lai et al., } \\
2020\end{array}$ \\
\hline \multirow[t]{4}{*}{$\begin{array}{l}\text { Teaching practices/ } \\
\text { teacher education/ } \\
\text { teacher training }\end{array}$} & $\begin{array}{l}\text { University students } \\
\text { from English } \\
\text { teaching-methods } \\
\text { course } \\
\text { [secondary English } \\
\text { student-teachers] }\end{array}$ & $\begin{array}{l}\text { Video-recorded } \\
\text { teaching lessons in } \\
\text { university English } \\
\text { methods-course } \\
\text { classroom \& teaching } \\
\text { videos recorded at } \\
\text { local field placements }\end{array}$ & $\begin{array}{l}\text { Sherry et } \\
\text { al.,2018 }\end{array}$ \\
\hline & $\begin{array}{l}\text { University students } \\
\text { from Bachelor of } \\
\text { Education } \\
\text { programme } \\
\text { (Geography } \\
\text { teaching) }\end{array}$ & $\begin{array}{l}\text { Video-recorded } \\
\text { Geography students' } \\
\text { microteaching lessons }\end{array}$ & $\begin{array}{l}\text { Van der } \\
\text { Westhuizen } \\
\text { \& Golightly } \\
\text { (2015) }\end{array}$ \\
\hline & $\begin{array}{l}\text { undergraduate } \\
\text { teaching (physical } \\
\text { education) course } \\
\text { [pre-service } \\
\text { teachers] }\end{array}$ & $\begin{array}{l}\text { Video-recorded } \\
\text { students' teaching } \\
\text { practice }\end{array}$ & $\begin{array}{l}\text { Colasante, } \\
2011\end{array}$ \\
\hline & $\begin{array}{l}\left({ }^{*}\right) 22 \text { pre-service } \\
\text { teachers (group 1) }\end{array}$ & $\begin{array}{l}\text { Video-recorded micro- } \\
\text { teaching videos }\end{array}$ & $\begin{array}{l}\text { Anderson et } \\
\text { al., } 2012\end{array}$ \\
\hline
\end{tabular}

Note: multiple-case study $(*)$ - only refer to the particular group/case which incorporated video-annotated peer feedback (i.e peer feedback activity conducted via video annotation) 
DEVELOPMENT

Vol. 10, No. 3, 2021, E-ISSN: 2226-6348 @ 2021 HRMARS

\section{The Proposed Guide for Video-annotated Peer feedback ACTIVITY}

The content of the nine (9) selected papers was analyzed via qualitative content analysis (Elo \& Kyngäs, 2008) based on the research question formulated. Information on the steps and phases of video-annotated peer feedback activities was initially identified and grouped. They were then named inductively and collated to illustrate the main steps, as illustrated in Figure 1. Based on the analysis, the main steps outlined were: (1) understanding objectives, task requirements, scope of annotations and analysis categories (2) getting acquainted with technological tools (3) composing and recording videos (4) annotating peers' videos (5) reviewing feedback in VA platform and (6) bridging knowledge gaps.

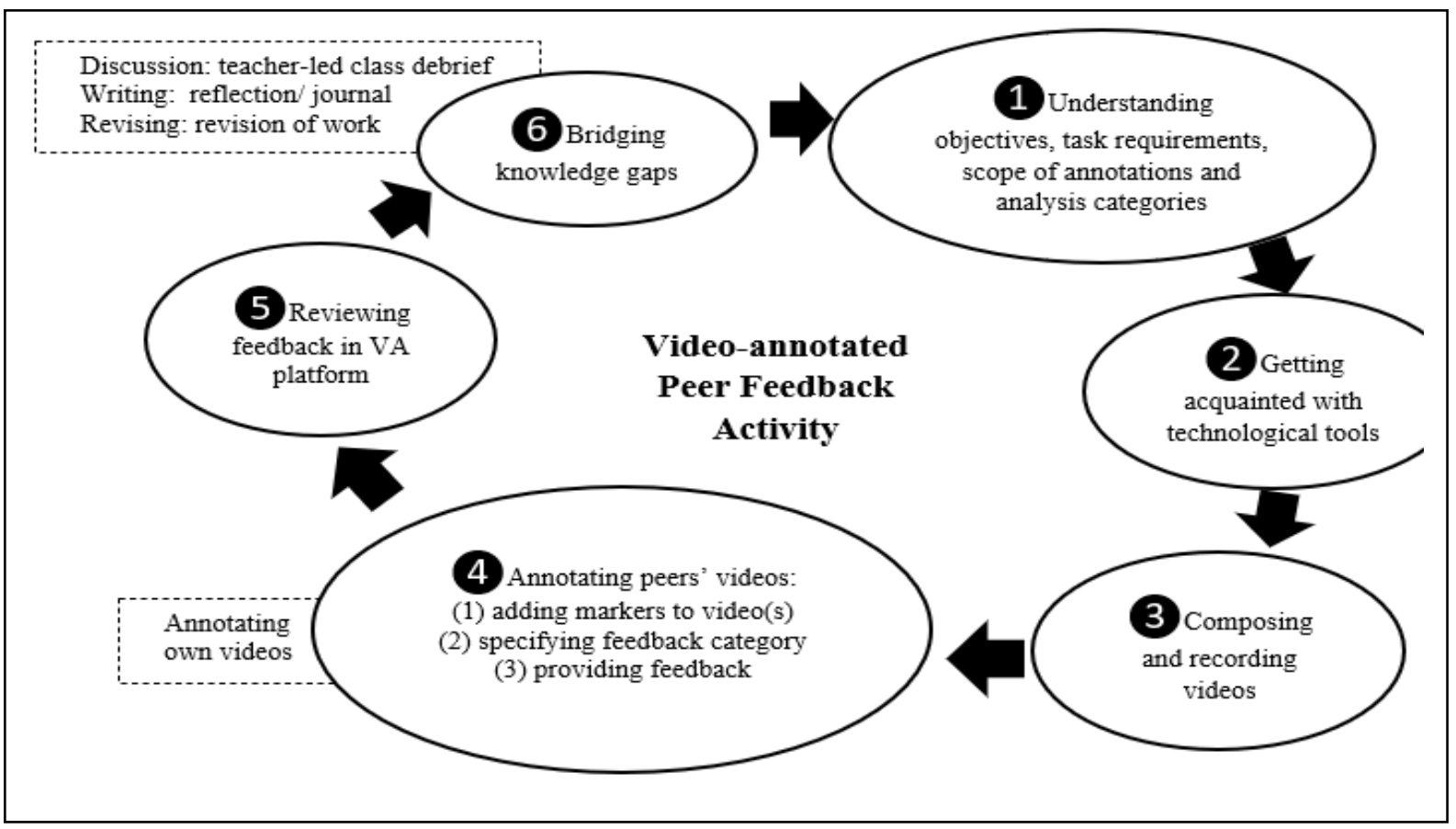

Figure 1. The proposed guide for video-annotated peer feedback activity

\section{Understanding objectives, task requirements, scope of annotations and analysis categories}

The first step plays a crucial role to ensure that students know what to do and what the predetermined goals and outcomes are. Identifying the intended learning outcomes and establishing a constructive alignment between video, activities and assessment were listed as activities for preparing the teaching with video annotation (Colasante \& Douglas, 2016). So, for students to be able to work towards achieving the learning outcomes, they need to first have a thorough understanding of the objectives and task requirements. Introduction of task objectives, purpose of peer feedback activity and procedures is essentially vital as it prepares the students to embark on video preparation and video analysis work at a later stage. For instance, in one of the selected studies (Lemon et al., 2013), the clearly defined objective of the MAT project, i.e "to identify and critique detailed early literacy issues in draft children's storybook" has mapped out the important details, such as the 'targeted videos' to be prepared as well as the task requirements. This will then help students to get an overview of how they should approach the task.

Besides, it was noted that a lot of planning and preparation work were carried out before students were led to prepare videos for the annotation task. For instance, in one of 
the selected studies (Baepler \& Reynolds, 2014), before the video production phase, students went through a few important phases such as brainstorming, idea-mapping, narrowing ideas and lastly establishing a focus on what they are going to do for the video project. So, having a good understanding of the task objectives, i.e the why and task requirements, i.e the what and how from the beginning will give students the direction for the upcoming learning activities. They do not only provide rationale but also let students see the relevance of the learning tasks.

Another important aspect is concerned with the scope of annotations. Depending on the intended learning outcomes, students need to know exactly what or which aspect(s) to focus on during video annotation. For instance, in the selected studies, student annotations were focused on effectiveness of the strategies employed in the raw shots (Baepler \& Reynolds, 2014) or positive examples of leadership characteristics and resolution techniques (Colasante \& Douglas, 2016). In another study (Hulsman \& Vloodt, 2015), students were instructed to annotate two successful performances and two poor performances. Similarly, nursing students in Lai et al. (2020) study were also required to specify the type of comment, as either positive or negative. In another study (Anderson et al., 2012), students were required to critique on aspects of their peer's presentation skills in micro-teaching videos.

Equally important is having a good understanding of the analysis categories or the criteria set for analysis so that students are aware of what to look for and annotate during video-annotated peer review. Depending on the course, objectives and topics, analysis categories are often predetermined by the instructor. For instance, in Colasante and Douglas' (2016) study which focused on the development of workplace skills to conduct business meetings and elicit discussions, analysis categories which are aligned to the curriculum, such as leadership characteristics and resolution techniques were set by teacher in MAT before the video analysis work (Colasante \& Douglas, 2016). As students need to analyze the videos based on teacher-set analysis categories in MAT, it is vital to ensure that they understand all these categories before the annotation work. Similarly, in annotating teaching practices videos (Colasante, 2011), students were required to do annotations with categories of analysis such as 'introductory activity', 'Demonstrations', 'Checking for understanding' and others which were predetermined. In another study (Anderson et al., 2012), pre-service teachers who were engaged in a video-annotated peer review activity were provided with a rubric, focusing on different dimensions of presentation skills, such as pace, clarity, posture, voice modulation, confidence and others to scaffold their comments. Understanding the rubric for assessment is thus pivotal. As evidenced in Lai et al.'s (2020) study, a 50-minute instructive course was conducted to help students in understanding the peer-assessment process, CCS rating scales and criteria for both quantitative and qualitative feedback. As students need to rate their peers' communication videos with communication and consultation skills scale, they need to have a good understanding of the scale before the peer assessment. It is also worth noting that a brief feedback training might be very helpful at an early stage of the process. As highlighted in previous peer feedback studies, peer review training can have positive impacts on students' revision work (Min, 2006) and development of student feedback literacy is crucial to enhancement of feedback processes (Carless \& Boud, 2018). To conclude, when objectives, task requirements, scope of annotations and analysis categories are communicated explicitly to the students, students will have a better idea on how to work towards achieving the intended learning outcomes in the video-annotated peer review at a later stage. 
DEVELOPMENT

Vol. 10, No. 3, 2021, E-ISSN: 2226-6348 ㄷ 2021 HRMARS

\section{Getting Acquainted with Technological Tools}

The second step is helping students to get the necessary technical support, either from instructive course, demonstration or video annotation training. As highlighted in one of the selected studies (Colasante \& Douglas, 2016), Property Service (PO) students were given technical support to video-record their role-plays of corporation meetings. Besides, MAT training slots were also arranged to provide sufficient technical support for the students so that they are ready to participate in the video-annotated activity in the next phase. In another study (Lai et al., 2020), the students were also briefed on how to log onto and post the videos in the annotation platform. A review and an analysis of a demonstration video were carried out before video preparation (Hulsman \& van der Vloodt, 2015). In Baepler and Reynolds' (2014) study, the class was provided with pocket video cameras to assist students in video preparation. Besides, students were also offered video editing assistance from university library media services and one-on-one technical consultation was also made available.

\section{Composing and Recording Videos}

The third step is concerned with preparing videos as input for the video-annotation task which will be conducted at a later stage. In Baepler and Reynolds' (2014) study, students were to create a 2-3 minute video, as an analogue of their written manifesto. Property-services students also took part in video preparation when they role-played owners corporation meetings (Colasante \& Douglas, 2016). As for clinical practices, Hulsman and van der Vloodt's (2015) study involved videos of students' consultation with simulated patients. Also, in another study, each student's 4-minute discussion/interview with the simulated patient was video recorded and uploaded to YouTube so that the URL can be retrieved and posted to NCPA (Lai et al., 2020). Videos for the MAT project which involved students in Teacher Education (Literacy) were generated and uploaded by students before they were engaged in a collaborative work to provide feedback to a paired peer on the draft book (Lemon et al., 2013). As for teaching practices, in Anderson et al.'s (2012) study, the 10 -minute selected section of the pre-service teachers' micro-teaching lessons was videotaped and uploaded onto EVA. Similarly, in another study (Sherry et al., 2018), the student-teachers' teaching lessons during English teaching-methods course were recorded by the instructor and uploaded for peer review at a later stage. Student-teachers were also responsible to compose and record lesson videos at local field placements. Geography students' micro-teaching lessons were video-recorded by one of the coursemates and were subsequently uploaded in VideoANT for annotation purposes (Westhuizen \& Golightly, 2015). Depending on the purpose and learning outcomes, the tasks can be designed as video assignments and this will in turn benefit students in many ways, in terms of the numerous opportunities for language practices, meaningful discussions generated or development of communication skills, particularly when group work is involved.

\section{Annotating Peers' Videos}

The fourth step is concerned with viewing, analyzing or evaluating peers' videos and providing feedback in video annotation platform. This involves selecting and adding a marker in the VA platform, specifying the feedback category and entering the notes of comment, depending on the scope of annotations and analysis categories which are normally predetermined. Some studies also provided rubric to scaffold students in the feedback giving process (see Anderson et al., 2012). 
It was also noted that annotating own videos was one of the essential steps in most of the selected studies. For instance, students were instructed to review their own videos individually before providing feedback to their peers (Hulsman \& Vloodt, 2015). In Colasante's (2011) study, the pre-service teachers were also required to watch their own teaching practice videos, mark it with the predefined markers set by the teacher before commenting on their peer's videos. In another study (Sherry et al., 2018), student-teachers were also required to annotate videos of themselves teaching in the university classroom, as well as at local field placements. Some studies, however, incorporated students' analysis of their own videos after the video-annotated peer review. The analysis of students' own videos came after obtaining peer feedback (Anderson et al., 2012; Colasante \& Douglas, 2016). Selfannotation is considered crucial as it pushes the students to self-reflect upon their own performances, thus it could function as an effective self-monitoring strategy for the students.

\section{Reviewing Feedback in VA Platform}

The next step is reviewing feedback in VA platform. Now, students are to read and respond to the comments in VA platform as to show their consensus or disagreement. Among the strategies commonly used were summarizing the peer comments or writing conclusions (see Baepler \& Reynolds, 2014; Lai et al., 2020), noting how improvements can be done in the future (see Lai et al., 2020) or how this learning would be applied in future (see Colasante, 2011). As highlighted by Luo (2016), asking students to review the peer feedback and summarize the revisions and changes made based on the feedback received will not only stimulate students to monitor and evaluate their own learning but most importantly, it will help to leverage the positive effects of peer feedback activity.

\section{Bridging Knowledge Gaps}

Based on the review, it was noted that a variety of activities have been used to help students in drawing a connection between what has been discussed and learned from video-annotated activity and the intended learning topics or practices or in other words, to translate the knowledge and skills to other learning experiences. This is significant in that it helps to link forward and let students see the relevance between what has been discussed in video annotation platform and the intended learning outcomes.

Most of the studies had teacher-led class debriefs after the video-annotated peer review. For instance, a conference was held after video-annotated peer review for instructor to clarify statements and strategies used by students in the videos as well as to offer advice on issues highlighted in annotation platform (Baepler \& Reynolds, 2014). Also, an in-class debrief was held with instructor after reviewing peer analysis and comparison with other groups' analysis (Colasante \& Douglas, 2016). In another study (Van der Westhuizen \& Golightly, 2015), after video-annotated peer review, the annotated micro-teaching videos were uploaded to LMS for students to watch and reflect upon. An in-class debrief which was characterized by further class discussions, reflections, provision of lecturer's input and respective groups' defence was held. In some studies, teacher feedback was provided in VA platform for students to review (Colasante, 2011; Colasante \& Douglas, 2016). However, in another study (Lemon et al., 2013), the overall feedback was provided by the teacher in a blog-like tool attached to MAT.

Some studies required students to write individual reflection/journals or reflective journals. After the video-annotated peer review, the pre-service teachers were required to 
write an individual reflection on their presentation skills and lessons with the feedback received (Anderson et al., 2012). In another study (Baepler \& Reynolds, 2014), two students' reflective writings were built into the digital portfolio projects. Students documented their learning in individual journals after reviewing feedback in annotation platform (Colsante \& Douglas, 2016).

Also, some studies required students to revise their work based on the feedback received. The final phase in portfolio project involved students revising and editing the project, which included the written and video drafts with the feedback obtained (Baepler \& Reynolds, 2014). Students were to record their second video after reviewing feedback in VA platform. In another study, students were to record their post-test video, the second teaching episode after obtaining feedback from their peers and instructor (Colasante, 2011). Also, an in-class presentation on completed child's storybook was conducted as the summation of video-annotated project in MAT (Lemon et al., 2013).

\section{Conclusion}

This paper has provided a review on the essential steps involved in conducting a videoannotated peer feedback activity. All in all, to engage students in a video-annotated peer feedback activity, these steps: (1) understanding objectives, task requirements, scope of annotations and analysis categories (2) getting acquainted with technological tools (3) composing and recording videos (4) annotating peers' videos (5) reviewing feedback in VA platform and (6) bridging their knowledge gaps are essential. However, they are not conclusive. Continual practice of research work is required to further confirm the steps. The proposed guide is expected to help researchers and practitioners in understanding the process and identify opportunities for further improvement. This study, however, is limited in that it included only a limited number of studies from Scopus and Google Scholar. Future studies could explore other databases, such as Web of Science to result in a more comprehensive review. Besides, more details such as the challenges and considerations for conducting video-annotated peer feedback activity can be further expanded in future studies. Future research might also explore the possible effects of these steps or the different design of each phase on student learning.

\section{Corresponding Author}

Catherine Nguoi Chui Lam

School of Education, Universiti Teknologi Malaysia, 81310 Skudai, Johor, Malaysia.

Email: catherinenguoi@yahoo.com

\section{References}

Aguillon, D. D. V., \& Monterola, S. L. C. (2020). Impact of online collaborative video annotation on STEM students' reflective thinking and academic self-discipline. International Journal of Innovative Science and Research Technology, 5 (1), 203-215.

Ahmad, N. A., \& Lidadun, B. P. (2017). Enhancing oral presentation skills through video presentation. International Journal of Social Sciences, 3(2), 385-397.

Anderson, K., Kennedy-Clark, S., \& Galstaun, V. (2012). Using Video Feedback and Annotations to Develop ICT Competency in Pre-Service Teacher Education. Australian Association for Research in Education (NJ1). 
Ardley, J., \& Hallare, M. (2020). The feedback cycle: Lessons learned with video annotation software during student teaching. Journal of Educational Technology Systems, 49(1), 94-112.

Ardley, J., \& Johnson, J. (2018). Video Annotation Software in Teacher Education: Researching University Supervisor's Perspective of a 21st-Century Technology. Journal of Educational Technology Systems, 47(4), 479-499.

Baepler, P., \& Reynolds, T. (2014). The digital manifesto: Engaging student writers with digital video assignments. Computers and composition, 34, 122-136.

Carless, D., \& Boud, D. (2018). The development of student feedback literacy: enabling uptake of feedback. Assessment \& Evaluation in Higher Education, 43(8), 1315-1325.

Chen, C. M., \& Chen, I. C. (2018). The effects of video-annotated listening review mechanism on promoting EFL listening comprehension. Interactive Learning Environments, 1-15.

Chen, C. M., Li, M. C., \& Lin, M. F. (2020). The effects of video-annotated learning and reviewing system with vocabulary learning mechanism on English listening comprehension and technology acceptance. Computer Assisted Language Learning, 1- 37.

Chiu, P. S., Chen, H. C., Huang, Y. M., Liu, C. J., Liu, M. C., \& Shen, M. H. (2016). A video annotation learning approach to improve the effects of video learning. Innovations in Education and Teaching International, 55(4), 459-469.

Colasante, M. (2011). Using video annotation to reflect on and evaluate physical education pre-service teaching practice. Australasian Journal of Educational Technology, 27(1). https://doi.org/10.14742/ajet.983

Colasante, M., \& Douglas, K. (2016). Prepare-Participate-Connect: Active learning with video annotation. Australasian Journal of Educational Technology, 32(4).

Colasante, M., \& Leedham, M. (2013). Motivation and satisfaction for vocational education students using a video annotation tool. In ASCILITE-Australian Society for Computers in Learning in Tertiary Education Annual Conference (pp. 167-177). Australasian Society for Computers in Learning in Tertiary Education.

Dawson, S., Pardo, A., Mirriahi, N., Gasevic, D., \& Kingstone, A. (2016). Using Video Annotation Software to Develop Student Self-Regulated Learning. Australian Government: Office for Learning and Teaching.

Douglas, K., Colasante, M., \& Kimpton, A. (2015). Exploiting emerging video annotation technology and industry engagement to authentically prepare students for the complex world of work. In Proceedings HERDSA Conference, Melbourne, Australia (pp. 60-71)

Elo, S., \& Kyngäs, H. (2008). The qualitative content analysis process. Journal of advanced nursing, 62(1), 107-115.

Evi-Colombo, A., Cattaneo, A., \& Bétrancourt, M. (2020). Technical and pedagogical affordances of video annotation: A literature review. Journal of Educational Multimedia and Hypermedia, 29(3), 193-226.

Grünewald, F., \& Meinel, C. (2015). Implementation and evaluation of digital e-lecture annotation in learning groups to foster active learning. IEEE Transactions on Learning Technologies, 8(3), 286-298.

Howard, C. D. (2012). Higher order thinking in collaborative video annotations: Investigating discourse modeling and the staggering of learner participation (Doctoral dissertation, Indiana University). 
Hulsman, R. L., \& van der Vloodt, J. (2015). Self-evaluation and peer-feedback of medical students' communication skills using a web-based video annotation system. Exploring content and specificity. Patient Education and Counseling, 98(3), 356-363.

Joksimović, S., Dowell, N., Gašević, D., Mirriahi, N., Dawson, S., \& Graesser, A. C. (2019). Linguistic characteristics of reflective states in video annotations under different instructional conditions. Computers in Human Behavior, 96, 211-222.

Kallio, H., Pietilä, A. M., Johnson, M., \& Kangasniemi, M. (2016). Systematic methodological review: developing a framework for a qualitative semi-structured interview guide. Journal of advanced nursing, 72(12), 2954-2965.

Lai, C. Y., Chen, L. J., Yen, Y. C., \& Lin, K. Y. (2020). Impact of video annotation on undergraduate nursing students' communication performance and commenting behaviour during an online peer-assessment activity. Australasian Journal of Educational Technology, 36(2), 71-88.

Lee, H. Y., \& List, A. (2019). Processing of texts and videos: A strategy-focused analysis. Journal of Computer Assisted Learning, 35(2), 268-282.

Lemon, N., Colasante, M., Corneille, K., \& Douglas, K. (2013). Video annotation for collaborative connections to learning: Case studies from an Australian higher education context. In Wankel, L., \& Blessinger, B. (Ed.), Increasing Student Engagement and Retention using Multimedia Technologies: Video Annotation, Multimedia Applications, Videoconferencing and Transmedia Storytellingpp (pp. 181 - 214). Emerald Group Publishing Limited. doi: 10.1108/S2044-9968(2013)000006F010

Luo, T. (2016). Enabling microblogging-based peer feedback in face-to-face classrooms. Innovations in Education and Teaching International, 53(2), 156-166.

Marçal, J., Borges, M. M., \& Viana, P. (2020). Learning physics through online video annotations. Education in the knowledge society (EKS), (21), 14.

McFadden, J., Ellis, J., Anwar, T., \& Roehrig, G. (2014). Beginning science teachers' use of a digital video annotation tool to promote reflective practices. Journal of Science Education and Technology, 23(3), 458-470.

Min, H. T. (2006). The effects of trained peer review on EFL students' revision types and writing quality. Journal of second language writing, 15(2), 118-141.

Mirriahi, N., Joksimović, S., Gašević, D., \& Dawson, S. (2018). Effects of instructional conditions and experience on student reflection: a video annotation study. Higher Education Research \& Development, 37(6), 1245-1259.

Moya, J. J. M., Robles, D. C., \& Desenne, P. (2015). Usability and Satisfaction in Multimedia Annotation Tools for MOOCs. Comunicar. Media Education Research Journal, 23(1).

Nilsson, P., \& Karlsson, G. (2019). Capturing student teachers' pedagogical content knowledge (PCK) using CoRes and digital technology. International Journal of Science Education, 41(4), 419-447.

Pérez-Torregrosa, A. B., Díaz-Martín, C., \& Ibáñez-Cubillas, P. (2017). The use of video annotation tools in teacher training. Procedia-Social and Behavioral Sciences, 237, 458464.

Perini, M., Cattaneo, A. A., \& Tacconi, G. (2019). Using Hypervideo to support undergraduate students' reflection on work practices: a qualitative study. International Journal of Educational Technology in Higher Education, 16(1), 1-16.

Sherry, M. B., Messier-Jones, L. M., \& Morales, J. (2018). Positioning in prospective secondary English teachers' annotations of teaching videos. English Teaching: Practice \& Critique. 
Tessier, L., \& Tremion, V. (2020). Exploring intercultural communication online: Video annotation in teacher education. Revista electrónica interuniversitaria de formación del profesorado, 23(1), 89-98.

Tülüce, H. S. (2018). Using a Web-based Video Annotation Tool in Pre-service Teacher Education: Affordances and Constraints. The European Conference on Language Learning 2018 Official Conference Proceedings.

Van Der Westhuizen, C. P., \& Golightly, A. (2015). Video annotation software application for thorough collaborative assessment of and feedback on microteaching lessons in geography education. Journal of Geography in Higher Education, 39(3), 420-436.

Wong, W. Y., \& Reimann, P. (2009, July). Web based educational video teaching and learning platform with collaborative annotation. In 2009 Ninth IEEE International Conference on Advanced Learning Technologies (pp. 696-700). IEEE.

Yu, H. Q., Pedrinaci, C., Dietze, S., \& Domingue, J. (2012). Using linked data to annotate and search educational video resources for supporting distance learning. IEEE Transactions on Learning Technologies, 5(2), 130-142.

Zhang, Q., \& Wu, F. (2015). Study on teacher-student interaction in flipped classroom based on video annotation learning platform. In Y. Li et al. (eds) State-of-the-Art and Future Directions of Smart Learning. Lecture Notes in Educational Technology. Springer, Singapore. https://doi.org/10.1007/978-981-287-868-7_29 